\title{
Women's empowerment and child growth faltering in Ethiopia: evidence from the Demographic and Health Survey
}

\author{
Alemayehu Gonie Mekonnen ${ }^{1 *} \mathbb{D}$, Daniel Bogale Odo ${ }^{2}$, Dabere Nigatu ${ }^{3}$, Adem Sav $^{4}$ and Kiya Kedir Abagero
}

\begin{abstract}
Background: Despite numerous national and international efforts to alleviate child growth faltering, it remains a global health challenge. There is a growing body of literature that recognizes the importance of women's empowerment in a wide range of public health topics, such as the utilization of maternal healthcare services, agricultural productivity, and child nutrition. However, in Ethiopia, the relationship between women's empowerment and child nutritional status is not studied at the national level. This study aimed to determine the association between women's empowerment and growth faltering in under-5 children in Ethiopia.

Methods: The data source for this analysis is the 2016 Ethiopian Demographic and Health Survey (EDHS): a nationally representative household survey on healthcare. The EDHS employed a two-stage stratified cluster sampling technique. We computed standard women's empowerment indices, following the Survey-based Women's emPowERment index approach. A multilevel logistic regression model that accounted for cluster-level random effects was used to estimate the association between women's empowerment and child growth faltering (stunting, wasting and underweight).
\end{abstract}

Results: Attitude to violence, social independence, and decision-making were the three domains of women's empowerment that were associated with child growth faltering. One standard deviation increase in each domain of empowerment was associated with a reduction in the odds of stunting: attitude towards violence ( $A O R=0.92 ; 95 \% \mathrm{Cl}$ $0.88-0.96 ; p<0.001)$, social independence $(\mathrm{AOR}=0.95 ; 95 \% \mathrm{Cl} 0.89-0.99 ; p=0.049)$, and decision-making $(\mathrm{AOR}=0.93$; $95 \% \mathrm{Cl} 0.87-0.99 ; p=0.023)$. Similarly, each standard deviation increase in attitude towards violence $(A O R=0.93$; $95 \% \mathrm{Cl} 0.89-0.98 ; p=0.008)$, social independence ( $\mathrm{OOR}=0.91 ; 95 \% \mathrm{Cl} 0.86-0.97 ; p=0.002$ ), and decision-making ( $A O R=0.92 ; 95 \% \mathrm{Cl} 0.86-0.99 ; p=0.020$ ) were associated with a decrease in the odds of having underweight child.

Conclusions: Ensuring women's empowerment both in the household and in the community could have the potential to decrease stunting and underweight in a rapidly developing country like Ethiopia. Policymakers and health professionals need to consider women's empowerment in this unique context to improve nutritional outcomes for children and alleviate growth faltering.

Keywords: Women's empowerment, Child growth faltering, EDHS

*Correspondence: alemayehugonie19@gmail.com

${ }^{1}$ College of Health Science, Debre Berhan University, Debre Berhan,

Ethiopia

Full list of author information is available at the end of the article

\section{Introduction}

In most societies, women are predominantly responsible for the selection, procurement, preparation, and provision of food for children in the household [1]. They play an important role in child feeding and make significant investments for their children [2]. As a result, 
the nutritional status of children is largely influenced by women's characteristics, including their level of empowerment at the household level and in the community.

Women's empowerment is a process and multidimensional by nature, and the concept operates at various levels [3]. Although there is no single commonly accepted definition of women's empowerment, most accepted is the ability of a woman to claim enabling resources, exercise voice and agency, and act on desires to transform her own life, in contexts where these abilities have been denied $[4,5]$. Different studies considered various sets of indicators to measure different dimensions of women's empowerment [6-8]. For instance, the Demographic and Health Survey (DHS) based studies which collect and disseminates accurate and nationally representative data on healthcare in developing countries have used two indicators to measure women's empowerment; decision-making at the household and women's attitude towards violence $[9,10]$. However, the recently published Survey-based Women's emPowERment (SWPER) index that based on DHS data of 34 African countries included some items that could better approximate the social independence aspect of women's empowerment [11]. Indeed, there are multifaceted discriminatory social and cultural norms, particularly in developing countries like Ethiopia, that can hinder women's ability in several ways [12].

There is a growing body of literature that recognizes the importance of women's empowerment in a wide range of public health topics such as the utilization of maternal healthcare services, agricultural productivity, and child nutrition [13-16]. Based on this evidence, women's empowerment is more important than household poverty in determining the nutritional status of children, and it influences child nutritional status through a range of mechanisms $[10,17]$. If women have freedom of plan of action and can decide on household income, they may have a high influence on household food choice to improve the diet and nutritional status of children [18, 19]. Hence, the lack of women's empowerment may be an underlying factor that contributes to child malnutrition $[7,20]$. Indeed, studies have examined the association between women's empowerment (despite dissimilarities in the operationalization) and child undernutrition. However, these studies have reported inconsistent results. For example, research from Bangladesh [21] and Benin [22] suggested that women's empowerment is associated with improved child feeding practices that affect child nutrition. On the other hand, a study from Mozambique [23] and Ghana [24] found no association between domains of women's empowerment and child growth faltering. Despite the mixed results, we could not find a published document on the relationship of different dimensions of women's empowerment and child nutrition within the Ethiopian context.

In Ethiopia, women's empowerment status is considered to be predominantly low [25] and food preparation is considered primarily women's duty [26]. Childhood undernourishment in the country remains highly prevalent. According to the Ethiopian Demographic and Health Survey (EDHS) 2016 report, 38\% of children are stunted, $10 \%$ are wasted and $24 \%$ are underweight [27]. Available evidence revealed that child mortality is about three times higher among women who had low decisionmaking ability than high decision-makers [28]. However, we do not know whether women's attitude towards domestic violence, social independence, and decisionmaking capabilities in the household, which have found to be important to child nutritional outcomes in various studies, actually have an impact on child nutrition in Ethiopia.

The current study aimed to determine the association between women's empowerment in terms of their attitude towards domestic violence, social independence, and decision-making in the household and growth faltering in Ethiopian children. To the best of our knowledge, there is no nationwide analysis that examines the relationship between such domains of women's empowerment and growth faltering among Ethiopian children. Indeed, efforts to reduce stunting, wasting and underweight health issues in Ethiopian children will not be fruitful without having adequate knowledge of the relationship between women's status both in the household and in the community with respect to childhood nutritional status. By understanding such association, our findings may help policymakers design sensitive programs that consider women's empowerment to alleviate childhood malnutrition in this context.

\section{Methods}

\section{Data sources and study population}

The data source for this analysis is the 2016 EDHS. The DHS is a principal source of data on a wide range of public health topics, including child nutrition and women's empowerment. This survey followed a two-stage stratified cluster sampling, in which clusters were selected from a list of enumeration areas, primary sampling units, formed for 2007 population census, and then households were randomly selected in each of the selected clusters (secondary sampling unit). Ethiopia is divided into nine geographical regions and two administrative cities. The 2016 EDHS was designed to collect representative samples from each administrative division and urban and rural areas separately. The survey target groups were children aged $0-5$ years, women aged $15-49$ years, and men 
aged 15-59 [27]. In the current study, the unit of analysis was children aged less than 5 years.

Five survey modules (questionnaires) were used for the 2016 EDHS. Of those, the woman's questionnaire was used to collect information from women of reproductive age (15-49 years) about their reproductive history and other child and household-related topics. In addition to the demographic issues, anthropometric information (height and weight) of under-five children were recorded. Details on sampling and data collection procedure of EDHS are described elsewhere [27]. The EDHS is approved by ORC Macro Institutional and by the Ethiopian ethical review board. Authors got permission from
(Additional file 1: Table S1). Of the 15 components, we retained three principal components that together explained $50 \%$ of variations, which were attitude towards violence against women, social independence, and decision-making (named based on what items they were loaded on). These components and the items it contains are presented as a Additional file 1: Table S2.

Most of the identified items were asked only to married or living with a partner (currently married) so that our analyses were restricted to this group. The following three equations used to calculate individual standardized scores both for the composite index and for the three principal components by using the same formula with SWPER computation [11].

$$
S_{i j}=\frac{\left[\left[\lambda_{1 j}\left(x_{1 i}-\bar{x}_{1}\right)\right]+\left[\lambda_{2 j}\left(x_{2 i}-\bar{x}_{2}\right)\right]+\cdots+\left[\lambda_{15 j}\left(x_{15 i}-\bar{x}_{15}\right)\right]\right]}{\sigma_{j}}
$$

ICF-DHS program to use the DHS data, accessed online (http://dhsprogram.com).

\section{Outcome variable}

Child growth faltering indicators: stunting, wasting and underweight were the outcome variables. Each child growth faltering indicator was defined using the anthropometric Z-scores assigned based on the World Health Organization (WHO) Child Growth Standards [29]. Stunting was defined as a height-for-age $\mathrm{Z}$ score less than minus two standard deviations (SD) below the median WHO Child Growth reference, wasting as a weight-forheight $\mathrm{Z}$-score less than negative $2 \mathrm{SD}$ below the reference median, and underweight as a weight-for-age $\mathrm{Z}$ score of less than negative $2 \mathrm{SD}$ below the reference median [30].

\section{Exposure variable}

Our main exposure variable was women's empowerment. We followed a method analogous to the SWPER index that was used by Ewerling [11] to compute a standard women's empowerment scores. The SWPER index was computed based on fifteen items extracted from DHS surveys of 34 African countries following methodical approaches and validated with the existing women's empowerment measures. The SWPER index better approximated the three (attitude to violence, social independence, and decision-making) dimensions of women's empowerment [11].

We applied principal component analysis (PCA) on 15 variables that were used to measure women's empowerment from different perspectives. Before PCA, we recategorised responses to these items so that higher value was given to categories indicating greater empowerment where $S_{\mathrm{ij}}$ is the individual standardized score for individual $i$ and component $j ; \mathrm{x}_{1 j}, \ldots, \mathrm{x}_{15 \mathrm{j}}$ are the individual values for variables $\mathrm{x}_{1}-\mathrm{x}_{15}$ included in the PCA analyses; $\sigma_{j}$ is the standard deviation of the predicted scores of each component $j$. The weight given to each of the 15 variables in each component $j$ is estimated using Eq. 2 bellow and presented (Additional file 1: Table S3).

$$
\lambda_{v j}=\frac{\varphi_{v j}}{\sigma_{v}}
$$

where $\phi_{v j}$ is the PCA loading for each of the variable $v$ in each domain $j$ and $\sigma_{v}$ is the standard deviation of each variable $v$ in the combined dataset.

Algebraically equation above can be simplified as follow:

$$
S_{i j}=\frac{\left[-\left(\sum_{v=1}^{15} \lambda_{v j} \bar{x}_{v}\right)+\left(\sum_{v=1}^{15}\left(\lambda_{v j} x_{v i}\right)\right)\right]}{\sigma_{j}}
$$

Based on the above formulas, we can estimate the scores both for the composite index and for the three dimensions of women's empowerment.

$$
\begin{aligned}
& \text { Attitude to violence score }=\frac{\left[(-0.915)+\left(\sum_{v=1}^{15}\left(\lambda_{v 1} x_{v i}\right)\right)\right]}{\begin{array}{c}
1.953 \\
(\text { component } 1)
\end{array}} \\
& \text { Social independence score }=\frac{\left[(-5.311)+\left(\sum_{v=1}^{15}\left(\lambda_{v 2} x_{v i}\right)\right)\right]}{\begin{array}{l}
1.44 \\
(\text { component } 2)
\end{array}} \\
& \text { Decision making score }=\frac{\left[(0.796)+\left(\sum_{v=1}^{15}\left(\lambda_{v 3} x_{v i}\right)\right)\right]}{\begin{array}{c}
1.283 \\
(\text { component } 3)
\end{array}}
\end{aligned}
$$


where $x_{\mathrm{vi}}$ is the value of variables $v$ for each individual $i$ and $\lambda_{\nu 0}-\lambda_{\mathrm{v} 3}$ are the variable weights that are found in the Additional file 1: Table S3. The standardization was made in such a way that it will have the properties of a standard normal distribution with mean $=0$ and standard deviation $=1$.

Besides, based on available evidence, other childrelated factors: acute respiratory infection and diarrhoea status, sex, age and the inter-birth interval [31, 32]; maternal-related factors: height, body mass index and smoking status [33]; and household and environmental-related factors: the source of drinking water, status of sanitation facility, types of cooking fuel, household wealth quintiles and place of residence [34] were adjusted in the analysis. Details on these covariates submitted as an additional file (Additional file 1: Table S4).

\section{Statistical analysis}

The weighted descriptive statistics were generated both for the dependent and independent variables. Bivariate and multivariable logistic regressions were used to assess the association between women's empowerment and stunting, wasting and underweight in children. As a result of a multistage cluster sampling approach used by the EDHS program, the data obtained from this program form hierarchy in which women nested within a household and households nested within a cluster. This sampling approach allows possibilities in which households from the same cluster may exhibit characteristics that are correlated with one another because of similar contextual conditions. For example, availability and accessibility of food could not be similar across clusters so that those children from the same cluster could have identical nutritional status than those from another cluster. Therefore, in addition to the conventional logistic regression models, we fitted a multilevel logistic regression with two levels that accounted the cluster level random effects (allowing dependence of child nutritional status within a cluster) by using melogit STATA command. The aforementioned covariates were adjusted for both the conventional and the multilevel logistic models. In the multilevel model, we first fitted model 1 to assess the level of intracluster correlation, and model 2 (crude model) to assess the association between women's empowerment and fuel use (i.e. adding each domain into an empty model). Then, model 3 was fitted to examine the independent effect of each empowerment domain controlling for other covariates.

Estimates were presented as adjusted odds ratio (AOR) with 95\% confidence intervals (CI) and expressed per one standard deviation increase in each empowerment domain (when women's empowerment in a specific domain moves away from the average/mean empowerment [which was zero in our case] of the normally distributed population by one standard deviation). A significant association was declared at a p-value of less than 0.05 .

\section{Results}

\section{Weighted descriptive statistics}

The total study population comprised of 9998 children, aged $0-5$ years. Of these, 5207 (51.1\%) children were male. Of the 8877 children, for whom height and age were recorded, 3405 (38.4\%) were stunted. Among 9,037 children for whom weight and age were recorded, 2,152 (23.8\%) were underweight. Of the 8895 children, for whom weight and height were recorded, $892(10.0 \%)$ were wasted. A total of 1096 (11.6\%) and 632 (6.7\%) mothers/ caregivers reported that their children had diarrhoea and acute respiratory infection (ARI), respectively, in the last two weeks preceding the survey. Short birth-interval (less than 34 months between successive births) was reported in $3801(38.0 \%)$ of the births. Less than one-tenth, 937 (9.4\%), of households had improved sanitation facility, 5534 (55.3\%) households had improved source of drinking water, and only 303 (3.0\%) households used clean fuel for cooking. Only 1032 (10.3\%) of households were urban dwellers (Table 1).

Table 2 presents the descriptive statistics of the domains of women's empowerment (Table 2). The descriptive statistics of each of the variable used to compute women's empowerment is attached as a Additional file 1: Table S3.

\section{Association of women's empowerment and child growth faltering}

In the unadjusted analysis, all the domains of women's empowerment were significantly negatively associated with stunting and underweight. Also, the attitude towards domestic violence against women and the social independence domains were significantly negatively associated with wasting (Table 3).

In the adjusted analysis (model without cluster-level random-effect), the odds of child stunting were $8 \%$ lower for each standard deviation increase in women's attitude towards domestic violence $(\mathrm{AOR}=0.92$; 95\% CI $0.88-0.96 ; p<0.001)$. The odds of stunting were $5 \%$ and $7 \%$ lower for each standard deviation increase in the social independence and the decision-making domains of women's empowerment (AOR $=0.95 ; 95 \%$ CI $0.89-0.99 ; p=0.049)$, and (AOR $=0.93$; $95 \%$ CI $0.87-$ $0.99 ; p=0.023)$, respectively. A one standard deviation increase in the domain of attitude towards domestic violence against women resulted in a 7\% reduction in the odds of having an underweight child (AOR $=0.93 ; 95 \%$ CI $0.89-0.98 ; p=0.008$ ). For each standard deviation 
Table 1 Weighted descriptive statistics of child nutritional status and other individual and household characteristics, 2016 EDHS

\begin{tabular}{|c|c|c|}
\hline Variables & Categories & $\mathrm{N}(\%)$ \\
\hline \multicolumn{3}{|l|}{ Child-related factors } \\
\hline \multirow[t]{2}{*}{ Stunting (Height-for-age) $(n=8877)$} & Not stunted & $5473(61.6)$ \\
\hline & Stunted & $3404(38.4)$ \\
\hline \multirow{2}{*}{$\begin{array}{l}\text { Wasting (Weight-for-height) } \\
\qquad(\mathrm{n}=8895)\end{array}$} & Not wasted & $8003(90.0)$ \\
\hline & Wasted & $892(10.0)$ \\
\hline \multirow{2}{*}{$\begin{array}{l}\text { Underweight (Weight-for-age) } \\
\qquad(\mathrm{n}=9037)\end{array}$} & Normal & $6885(76.2)$ \\
\hline & Underweight & $2152(23.8)$ \\
\hline \multirow[t]{2}{*}{ Sex of the child $(n=9998)$} & Male & $5207(51.1)$ \\
\hline & Female & $4791(48.9)$ \\
\hline \multirow{5}{*}{$\begin{array}{l}\text { Current age of the child in years } \\
(n=9450)\end{array}$} & $<1$ & $2076(22.0)$ \\
\hline & 1 & $1800(19.0)$ \\
\hline & 2 & $1766(18.7)$ \\
\hline & 3 & $1827(19.3)$ \\
\hline & 4 & $1981(21.0)$ \\
\hline \multirow[t]{2}{*}{ Inter-birth interval $(n=9998)$} & Not short & $6197(62.0)$ \\
\hline & Short (<34 months) & $3801(38.0)$ \\
\hline \multicolumn{3}{|l|}{ Health status of children } \\
\hline \multirow[t]{2}{*}{ ARI in the last two weeks $(n=9450)$} & No & $8818(93.3)$ \\
\hline & Yes & $632(6.7)$ \\
\hline \multirow{2}{*}{$\begin{array}{l}\text { Diarrhea in the last two weeks } \\
(n=9450)\end{array}$} & No & $8354(88.4)$ \\
\hline & Yes & $1096(11.6)$ \\
\hline \multicolumn{3}{|l|}{ Maternal related factors } \\
\hline \multirow[t]{2}{*}{ Stature (height) $(n=9997)$} & Not short $(\geq 145 \mathrm{~cm})$ & $9772(97.8)$ \\
\hline & Short $(<145 \mathrm{~cm})$ & $226(2.2)$ \\
\hline \multirow[t]{3}{*}{ BMI (weight/height) $(n=9998)$} & Thin & $522(5.2)$ \\
\hline & Normal & $8872(88.8)$ \\
\hline & Overweight/obese & $604(6.0)$ \\
\hline \multirow[t]{2}{*}{ Cigarette smoking status ( $\mathrm{n}=9998)$} & No & $9921(99.2)$ \\
\hline & Yes & $77(0.8)$ \\
\hline \multicolumn{3}{|l|}{ Household factors } \\
\hline \multirow[t]{2}{*}{ Source of drinking water $(n=9998)$} & Improved & $5534(55.3)$ \\
\hline & Not improved & $4464(44.7)$ \\
\hline \multirow[t]{2}{*}{ Sanitary facility $(n=9998)$} & Improved & $937(9.4)$ \\
\hline & Not improved & $9061(90.6)$ \\
\hline \multirow[t]{2}{*}{ Cooking fuel $(n=9998)$} & Clean & $303(3.0)$ \\
\hline & Polluting & $9695(97.0)$ \\
\hline \multirow[t]{5}{*}{ Household wealth index $(n=9998)$} & Poorest & $2353(23.5)$ \\
\hline & Poorer & $2336(23.4)$ \\
\hline & Middle & $2104(21.4)$ \\
\hline & Richer & $1828(18.0)$ \\
\hline & Richest & $1377(13.7)$ \\
\hline \multirow[t]{2}{*}{ Place of residence $(n=9998)$} & Rural & $8966(89.7)$ \\
\hline & Urban & $1032(10.3)$ \\
\hline
\end{tabular}

$A R I$ acute respiratory infection, $B M I$ body mass index, $\mathrm{cm}$ centimetre
Table 2 Descriptive statistics of the domains of women's empowerment, 2016 EDHS

\begin{tabular}{llll}
\hline Statistics & \multicolumn{3}{l}{ Domains of women's empowerment } \\
\cline { 2 - 4 } & $\begin{array}{l}\text { Attitude } \\
\text { to violence }\end{array}$ & $\begin{array}{l}\text { Social } \\
\text { independence }\end{array}$ & Decision-making \\
\hline Mean & 0.00 & 0.00 & 0.00 \\
Standard deviation & 1.00 & 1.00 & 1.00 \\
Minimum & -1.52 & -2.45 & -3.75 \\
Maximum & 1.54 & 6.41 & 0.43 \\
Frequency & 9914 & 9914 & 9914 \\
\hline
\end{tabular}

Values of women's empowerment domains were standardized, with mean of 0 and SD of 1

increase in social independence and decision-making domains of women's empowerment, the odds of having an underweight child decreased by $9 \%(\mathrm{AOR}=0.91 ; 95 \%$ CI $0.86-0.97 ; p=0.002)$ and $8 \%(\mathrm{AOR}=0.92 ; 95 \% \mathrm{CI}$ $0.86-0.99 ; p=0.020$ ), respectively (Table 3 ).

In the model with a cluster-level random effect term, the only women's empowerment domain that significantly associated with child stunting was the attitude towards domestic violence against women $(\mathrm{AOR}=0.91$; 95\% CI $0.87-0.96 ; p<0.001)$. In the same model, all domains were significantly negatively associated with having an underweight child. For example, as one standard deviation increased in the attitude towards domestic violence against women, the odds of having underweight child decreased by $7 \%$ (AOR $=0.93$; $95 \%$ CI $0.89-0.99$; $p=0.015)$. For each standard deviation increase in the domains of social independence and decision-making, the odds for having underweight child were associated with a $8 \%$ decrease for each (AOR $=0.92$; 95\% CI $0.86-$ $0.99 ; p=0.017)$ and $(\mathrm{AOR}=0.92 ; 95 \%$ CI $0.85-0.98$; $p=0.017$ ) (Table 3).

The overall outputs from the two adjusted models (a model without cluster-level random effect and a model with a cluster-level random effect term) is attached as a Additional file 1. In those models, the independent effects of other child-related factors, maternal factors, and household and environmental-related factors are displayed (Additional file 1: Table S3).

\section{Discussions}

Child undernutrition is not only caused by the lack of food but can also be affected by other factors, including women's empowerment [35]. As underscored by the findings of this study, in order to reach optimal nutritional status, women need to feel empowered as they may have a high influence on food selection, procurement, preparation and feeding for children to improve their nutritional status [36]. Previous studies have noted 
Table 3 Fixed and random effect of the model to assess the relationship between women's empowerment and child growth faltering in Ethiopia, 2016 EDHS

\begin{tabular}{|c|c|c|c|c|c|c|}
\hline \multirow{3}{*}{$\begin{array}{l}\text { Domains of women's } \\
\text { empowerment }\end{array}$} & \multicolumn{6}{|c|}{ Growth faltering indicators (child nutritional status) } \\
\hline & \multicolumn{2}{|l|}{ Stunting $(\mathrm{n}=8076)$} & \multicolumn{2}{|l|}{ Wasting $(n=8142)$} & \multicolumn{2}{|c|}{ Underweight $(\mathrm{n}=8241)$} \\
\hline & Crude odds ratio & $P$ value & Crude odds ratio & $P$ value & Crude odds ratio & $P$ value \\
\hline Attitude to violence & $0.85(0.71,0.88)$ & $<0.001$ & $0.91(0.86,0.97)$ & 0.004 & $0.84(0.80,0.88)$ & $<0.001$ \\
\hline Social independence & $0.81(0.78,0.86)$ & $<0.001$ & $0.86(0.81,0.93)$ & $<0.001$ & $0.77(0.73,0.81)$ & $<0.001$ \\
\hline \multirow[t]{3}{*}{ Decision-making } & $0.86(0.81,0.91)$ & $<0.001$ & $0.95(0.87,1.03)$ & 0.213 & $0.82(0.77,0.88)$ & $<0.001$ \\
\hline & Adjusted odds ratio & $P$ value & Adjusted odds ratio & $P$ value & Adjusted odds ratio & $P$ value \\
\hline & \multicolumn{6}{|c|}{${ }^{1}$ Multivariable logistic regression without random effect ${ }^{R}$} \\
\hline Attitude to violence & $0.92(0.88,0.96)$ & $<0.001$ & $0.96(0.90,1.03)$ & 0.333 & $0.93(0.89,0.98)$ & 0.008 \\
\hline Social independence & $0.95(0.89,0.99)$ & 0.049 & $0.95(0.88,1.03)$ & 0.494 & $0.91(0.86,0.97)$ & 0.002 \\
\hline Decision-making & $0.93(0.87,0.99)$ & 0.023 & $1.03(0.95,1.13)$ & 0.246 & $0.92(0.86,0.99)$ & 0.020 \\
\hline Attitude to violence & $0.91(0.87,0.96)$ & $<0.001$ & $0.97(0.90,1.04)$ & 0.371 & $0.93(0.89,0.99)$ & 0.015 \\
\hline Social independence & $0.96(0.90,1.01)$ & 0.138 & $0.96(0.88,1.04)$ & 0.299 & $0.92(0.86,0.99)$ & 0.017 \\
\hline Decision-making & $0.94(0.88,1.01)$ & 0.088 & $1.01(0.92,1.11)$ & 0.782 & $0.92(0.85,0.98)$ & 0.017 \\
\hline
\end{tabular}

${ }^{R}$ Adjusted for child-related factors (sex, age, acute respiratory infection, diarrhoea, and birth interval), maternal factors (body max index, stature (height), and smoking status), household and environmental-related factors (source of drinking water, sanitation facility, type of cooking fuel, wealth index, and location of the cluster), and to one another

1 Model without random effect, but used $\mathrm{Cl}$ that accounted for the highest level of clustering (e.g. survey cluster)

2 Model with cluster-level (primary sampling point) random effect

that women's empowerment reduces the time allocated to childcare and child feeding which, in turn, can lead to poor nutritional outcomes for children [37]. On the other hand, women's decision-making power can have a positive impact on reducing childhood stunting in that those who have household decisional role can allocate the available resource and select nutritious food for their children $[7,21,38]$.

In this study, attitude towards domestic violence against women (individually), social independence (socially), and decision-making abilities (in the household) were the three dimensions of women's empowerment that were significantly associated with child undernutrition (stunting and underweight). More specifically, in both models (without and with cluster-level random effects), women's disapproval attitude towards violence against women was associated with a reduction in child stunting. This adds to the remarkable body of evidence on the positive impact of women's disapproval attitude towards violence on the reduction of child stunting in developing counties where there is very limited evidence (e.g. Ethiopia). This finding could be explained by considering the traditional gender roles that are largely present within Ethiopia. It could be argued that because women are the primary caretakers of children in the household, they could likely have the bargaining power to influence daily household purchases, including variety and adequate food, and appropriate child feeding and childcare practice $[23,36]$.

In the model without cluster-level random effects, an increase in women's social independence was associated with a decrease in childhood stunting. This result confirms that women's social status impacts child nutritional status. This finding has paramount public health importance in countries like Ethiopia because gender norms are existed and practiced in women's daily life and there are social and cultural norms that restrict women's ability to make choices $[39,40]$. In agreement with our finding, a literature review on associations between women's autonomy and child nutrition by Carlson et al. 2015, indicated a significant association between social independence and childhood stunting [41]. For example, women's liberty of movement and social support were inversely associated with childhood stunting in Andhra Pradesh, India [42], rural Nicaragua [43], and Burkina Faso [17]. Similarly, the literature review also reported a significant association between women's freedom of movement and reduction of child stunting [41]. The possible explanation for this could be that when they are socially independent, women have more chance to participate in social events, where they may share child feeding information, and have the ability to justify expenditure on child food. Overall, this can have a profound effect on child nutritional status. 
Additionally, we found that one standard deviation increase in women's decision-making domain was associated with a $7 \%$ reduction in the odds of stunting. However, previous studies have reported varied results [23, 37, 44]. For example, in line with our finding, Imai et al. [45], Alkire et al. [46] and Salawu et al. [37] reported a significant association between women's decisionmaking power and the reduction of childhood stunting. On the contrary, women's decision-making power was not significantly associated with childhood stunting in Mozambique [23] in Lao People's Democratic Republic [47]. Also, being decision-makers in the household had no association with child malnutrition in Pakistan [44]. Regardless of these variations, it is important to note that when women have decisional autonomy on household income allocation, daily household purchase and freedom of movement, they could have opportunity to select and feed their children adequately, and this can lead to potential childhood stunting.

Concerning child's weight-for-age (underweight) status, we found that having disapproval attitude towards violence against women was negatively associated with childhood underweight. This finding is consistent with previous research reported from Bangladesh [48] and evidence from demographic and health surveys from developing countries [49]. One interpretation for these finding is that the acceptance of violence against women could allow their partners to dominate household resource and suppress women's decisional role including right to allocate income, purchase items and child feeding practices. As such, women may feel forced to resort to child feeding practices, which are readily available at home, less expensive and also less nutritious.

Moreover, an increase in women's social independence and participation in decision-making was associated with a decrease in the chance of having an underweight child. In line with our finding, women's freedom of movement and independence were linked with child underweight in India [38]. If women participated in decision-making at household, the chance of having underweight child decreased [50]. Additionally, even though it was not linked to a specific domain of women's empowerment, Imai et al. reported the association between women's empowerment and child underweight [45]. The fact that socially independent women have a chance to meet others and share knowledge, and those who have decisional role could allocate adequate resources, could be one potential explanation of our finding.

In the cluster-level random effect model, the only women's empowerment domain that significantly and inversely associated with childhood stunting was women's attitude towards domestic violence. In the same model, all three domains of women's empowerment were inversely associated with being underweight. Given that the statistical model considered variation (i.e., allowed dependence/similarity of the outcome within the same cluster), this finding points to the idea that children's nutritional status and women's empowerment could vary from place to place. The concept is even more important in Ethiopia because there are substantial places of residence where information on child feeding practice and importance is hard to reach. Moreover, gender imbalances exist in different aspects including in the division of labour, access to resources, distribution of income, decision-making and cultural norms that favour toward males in the country.

Finally, results from both models (with and without cluster-level random effects) demonstrated that the three domains of women's empowerment had no association with wasting in children. As mentioned above, increasing women's empowerment in all these dimensions would improve child nutritional outcomes and initiate measures to accelerate progress in line with the sustainable development goals.

\section{Limitation of the study}

Despite its strengths, this study has some limitations that must be acknowledged. Although our study employed national representative data, the index that we applied did not include all the variables that could measure women's status (e.g. ownership status of women on properties such as land and house). Furthermore, most of the woman's status indicators collected by the DHS applied to only married or currently married women and missed single, widowed, divorced, and separated women. Authors also acknowledge the limitations associated with self-reported data and the limitations that the multivariable model may have missed some variables that could potentially have been relevant.

\section{Conclusions}

This is one of the few studies that shed light on the understanding of child nutrition and women's empowerment in a rapidly developing country like Ethiopia. Ensuring women's empowerment both in the household and in the community could have a potential to decrease stunting and underweight in Ethiopia. Policymakers and health professionals need to consider women's empowerment in this unique context to improve nutritional outcomes for children and alleviate growth faltering. 


\section{Supplementary Information}

The online version contains supplementary material available at https://doi. org/10.1186/s12905-021-01183-x.

Additional file 1: Table S1. Coded/scaled items used in the development of woman's empowerment index. Table S2. Domains of women's empowerment with items in the component. Table S3. List of variables used in the PCA, component loadings and weight of each variable and all items required to compute a standard score of woman's empowerment in each component/domain. Table S4. Details of the variables included in the regression models.

\section{Abbreviations}

ARI: Acute Respiratory Infection; AOR: Adjusted Odds Ratio; Cl: Confidence Interval; DHS: Demographic Health Survey; PCA: Principal Component Analyses; SWPER: Survey-based Women's emPowERment index; SD: Standard Deviation.

\section{Acknowledgements}

Not applicable.

\section{Authors' contributions}

$A G M$ and DBO conceived and designed the study, developed the methodology and interpreted the data. DBO analyzed the data. AGM, DBO, DN, AS and KKA drafted and substantively revised the manuscript. All authors approved the submitted version of the manuscript and agreed both to be personally accountable for the author's own contributions and to ensure that questions related to the accuracy or integrity of any part of the manuscript.

\section{Funding}

Not applicable.

\section{Availability of data and materials}

The datasets used and/or analyzed during this study can be accessed upon reasonable request from the DHS program website (available at http://dhspr ogram.com)

\section{Ethics approval and consent to participate}

The 2016 EDHS survey protocol are approved by ORC Macro Institutional and by Ethiopian ethical review board. The authors got permission from the ICFDHS program to use the DHS data and accessed at http://dhsprogram.com.

\section{Consent to publication}

Not applicable.

\section{Competing interests}

The authors declared that they have no competing interests.

\section{Author details \\ ${ }^{1}$ College of Health Science, Debre Berhan University, Debre Berhan, Ethiopia. ${ }^{2}$ College of Health Sciences, Arsi University, Asela, Ethiopia. ${ }^{3}$ School of Public Health, College of Medicine and Health Sciences, Bahir Dar University, Bahir Dar, Ethiopia. ${ }^{4}$ School of Public Health and Social Work, Faculty of Health, Queensland University of Technology, Brisbane, QLD, Australia. ${ }^{5}$ Non Com- municable Disease Directorate, Armauer Hansen Research Institute, Addis Ababa, Ethiopia.}

Received: 1 September 2020 Accepted: 18 January 2021 Published online: 30 January 2021

\section{References}

1. Jones R, Haardörfer R, Ramakrishnan U, Yount KM, Miedema S, Girard AW. Women's empowerment and child nutrition: the role of intrinsic agency. SSM Popul Health. 2019;9:100475.
2. Folaranmi OO. Women empowerment as a determinant of investments in children in selected rural communities in Nigeria. Afr RES Rev. 2013;7(4):138-61.

3. Pennington A, Orton L, Nayak S, Ring A, Petticrew M, Sowden A, White $M$, Whitehead $M$. The health impacts of women's low control in their living environment: a theory-based systematic review of observational studies in societies with profound gender discrimination. Health Place. 2018;51:1-10

4. Kabeer N. Resources, agency, achievements: reflections on the measurement of women's empowerment. Dev Change. 1999;30(3):435-64.

5. Riddle AY, Kroeger CM, Ramage AK, Bhutta ZA, Kristjansson E, Vlassoff C, Taljaard M, Skidmore B, Welch V, Wells GA. PROTOCOL: the effects of empowerment-based nutrition interventions on the nutritional status of adolescent girls in low-and middle-income countries. Campbell Syst Rev. 2019. https://doi.org/10.1002/cl2.1042.

6. Cunningham K, Ruel M, Ferguson E, Uauy R. Women's empowerment and child nutritional status in South Asia: a synthesis of the literature. Matern Child Nutr. 2015;11(1):1-9. https://doi.org/10.1111/mcn.12125.

7. Sethuraman K, Lansdown R, Sullivan K. Women's empowerment and domestic violence: the role of sociocultural determinants in maternal and child undernutrition in tribal and rural communities in South India. Food Nutr Bull. 2006;27(2):128-43.

8. Sharma A, Kader M. Effect of women's decision-making autonomy on infant's birth weight in rural Bangladesh. Int Sch Res Not. 2013;2013:8. https://doi.org/10.1155/2013/159542.

9. Na M, Jennings L, Talegawkar SA, Ahmed S. Association between women's empowerment and infant and child feeding practices in subSaharan Africa: an analysis of Demographic and Health Surveys. Public Health Nutr. 2015;18(17):3155-65.

10. Jamal H. Mother's empowerment and child malnutrition: evidence from Pakistan. Munich Pers RePEc Arch. 2018;(87949). https://mpra.ub.unimuenchen.de/id/eprint/87949.

11. Ewerling F, Lynch JW, Victora CG, van Eerdewijk A, Tyszler M, Barros AJ. The SWPER index for women's empowerment in Africa: development and validation of an index based on survey data. Lancet Glob Health. 2017;5(9):e916-23.

12. Elsayed A, Roushdy R. Empowering women under social constraints: evidence from a field intervention in rural Egypt. IZA Discussion Paper No. 11240. https://ssrn.com/abstract=3097358.

13. Malapit HJ, Kadiyala S, Quisumbing AR, Cunningham K, Tyagi P. Women's empowerment in agriculture, production diversity, and nutrition: evidence from Nepal. IFPRI Discuss Pap 01313. 2013. https://papers.ssrn. com/sol3/papers.cfm?abstract_id=2405710.

14. Abreha SK, Walelign SZ, Zereyesus YA. Associations between women's empowerment and children's health status in Ethiopia. PLOS ONE. 2020;15(7):e0235825. https://doi.org/10.1371/journal.pone.0235825.

15. Tiruneh FN, Chuang K, Chuang Y. Women's autonomy and maternal healthcare service utilization in Ethiopia. BMC Health Serv Res. 2017;17:718. https://doi.org/10.1186/s12913-017-2670-9.

16. Sebayang SK, Efendi F, Astutik E. Women's empowerment and the use of antenatal care services: analysis of demographic health surveys in five Southeast Asian countries. Women Health. 2019;59(10):1155-71.

17. Heckert J, Olney DK, Ruel MT. Is women's empowerment a pathway to improving child nutrition outcomes in a nutrition-sensitive agriculture program? Evidence from a randomized controlled trial in Burkina Faso. Soc Sci Med. 2019;233:93-102.

18. SPRING. The Role of Increased Income and Women's Empowerment on Nutrition: A Review of Communities' Perception of Changes due to Two Feed the Future Activities in Rwanda. Arlington, VA: USAID/Strengthening Partnerships, Results, and Innovations in Nutriti. 2014;(November). http:// livestocklab.ifas.ufl.edu/media/livestocklabifasufledu/pdf-/Nutrition-Sensi tive-Livestock-Interventions-1.10.2019.pdf

19. Abate KH, Belachew T. Women's autonomy and men's involvement in child care and feeding as predictors of infant and young child anthropometric indices in coffee farming households of Jimma zone, South West of Ethiopia. PLoS ONE. 2017;12(3):e0172885. https://doi.org/10.1371/ journal.pone.0172885.

20. Khan S, Zaheer S, Safdar NF. Determinants of stunting, underweight and wasting among children< 5 years of age: evidence from 2012-2013 Pakistan demographic and health survey. BMC Public Health. 2019;19(1):358. https://doi.org/10.1186/s12889-019-6688-2. 
21. Holland C, Rammohan A. Rural women's empowerment and children's food and nutrition security in Bangladesh. World Dev. 2019;124:104648.

22. Alaofè H, Zhu M, Burney J, Naylor R, Douglas T. Association between women's empowerment and maternal and child nutrition in Kalalé district of Northern Benin. Food Nutr Bull. 2017;38(3):302-18.

23. Deutsch J, Silber J. Women's empowerment and child malnutrition: the case of mozambique. S Afr J Econ. 2019;87(2):139-79. https://doi. org/10.1111/saje.12223.

24. Malapit HJ, Quisumbing AR. What dimensions of women's empowerment in agriculture matter for nutrition in Ghana? Food Policy. 2015;52:54-63.

25. Tadesse M, Teklie H, Yazew G, Gebreselassie T. Women's empowerment as a determinant of contraceptive use in Ethiopia further analysis of the 2011 Ethiopia demographic and health survey. DHS Further Analysis Reports. 2013; 82. Calverton, Maryland, USA ICF Int.

26. Alemu B, Asnake M. Women's empowerment in Ethiopia: new solutions to ancient problems. Pathfinder International/Ethiopia, Addis Ababa. 2007. http://www2.pathfinder.org/site/DocServer/PI_WE_paper_final .pdf?doclD $=10202$.

27. Central Statistical Agency (CSA) [Ethiopia] and ICF. 2016. Ethiopia demographic and health survey 2016. Addis Ababa, Ethiopia, and Rockville, Maryland, USA: CSA and ICF.

28. Fantahun M, Berhane $Y$, Wall S, Byass $P$, Högberg U. Women's involvement in household decision-making and strengthening social capital_crucial factors for child survival in Ethiopia. Acta Paediatr. 2007;96(4):582-9. https ://doi.org/10.1111/j.1651-2227.2007.00147.x.

29. Croft TN, Marshall AM, Allen CK, Arnold F, Assaf S, Balian S. Guide to DHS statistics. Rockville: ICF; 2018.

30. World Health Organization. WHO child growth standards: length/heightfor-age, weight-for-age, weight-for-length, weight-for-height and body mass index-for-age: methods and development. World Health Organization; 2006. https://apps.who.int/iris/bitstream/handle/10665/43413 1924154693X_eng.pdf.

31. Nshimyiryo A, Hedt-Gauthier B, Mutaganzwa C, Kirk CM, Beck K, Ndayisaba A, Mubiligi J, Kateera F, El-Khatib Z. Risk factors for stunting among children under five years: a cross-sectional population-based study in Rwanda using the 2015 Demographic and Health Survey. BMC Public Health. 2019;19(1):1-10.

32. Mzumara B, Bwembya P, Halwiindi H, Mugode R, Banda J. Factors associated with stunting among children below five years of age in Zambia: evidence from the 2014 Zambia demographic and health survey. BMC Nutr. 2018;4(1):51.

33. Wemakor A, Garti H, Azongo T, Garti H, Atosona A. Young maternal age is a risk factor for child undernutrition in Tamale Metropolis, Ghana. BMC Res Notes. 2018;11(1):877. https://doi.org/10.1186/s13104-018-3980-7.

34. Yaya S, Oladimeji O, Odusina EK, Bishwajit G. Household structure, maternal characteristics and children's stunting in sub-Saharan Africa: evidence from 35 countries. Int Health. 2020. https://doi.org/10.1093/inthealth/ ihz105.

35. Sinha RK, Dua R, Bijalwan V, Rohatgi S, Kumar P. Determinants of stunting, wasting, and underweight in five high-burden pockets of four Indian states. Indian J Commun Med Off Publ Indian Assoc Prev Soc Med. 2018;43(4):279.

36. Pandey VL, Dev SM, Jayachandran U. Impact of agricultural interventions on the nutritional status in South Asia: a review. Food Policy. 2016;62:2840. https://doi.org/10.1016/j.foodpol.2016.05.002.

37. Salawu MB, Rufai AM, Salman KK, Ogunniyi IA. The influence of women empowerment on child nutrition in rural Nigeria. https://media.africaport al.org/documents/BMGF-013.pdf.
38. Shome S, Pal M, Bharati P. Influence of maternal autonomy and socioeconomic factors on birth weight of infants in India. Malays J Nutr. 2018;24(1):35-42.

39. Seema J. Social norms as a barrier to women's employment in developing countries. World Institute for Development Economic Research (UNUWIDER); 2019. https://www.nber.org/papers/w27449.

40. Bekana DM. Policies of gender equality in Ethiopia: the transformative perspective. Int J Public Adm. 2020;43(4):312-25. https://doi. org/10.1080/01900692.2019.1628060.

41. Carlson GJ, Kordas K, Murray-Kolb LE. Associations between women's autonomy and child nutritional status: a review of the literature. Matern Child Nutr. 2015;11(4):452-82. https://doi.org/10.1111/mcn.12113.

42. Shroff M, Griffiths P, Adair L, Suchindran C, Bentley M. Maternal autonomy is inversely related to child stunting in Andhra Pradesh. India Matern Child Nutr. 2009;5(1):64-74. https://doi.org/10.111 1/j.1740-8709.2008.00161.x.

43. Vollmer S, Harttgen K, Subramanyam MA, Finlay J, Klasen S, Subramanian SV. Association between economic growth and early childhood undernutrition: evidence from 121 Demographic and Health Surveys from 36 low-income and middle-income countries. Lancet Glob Health. 2014;2(4):e225-34. https://doi.org/10.1016/\$2214-109X(14)70025-7.

44. Shafiq A, Hussain A, Asif M, Hwang J, Jameel A, Kanwel S. The effect of "women's empowerment" on child nutritional status in Pakistan. Int J Environ Res Public Health. 2019;16(22):4499. https://doi.org/10.3390/ijerp h16224499.

45. Imai KS, Annim SK, Kulkarni VS, Gaiha R. Women's empowerment and prevalence of stunted and underweight children in rural India. World Dev. 2014;62:88-105. https://doi.org/10.1016/j.worlddev.2014.05.001.

46. Alkire S, Meinzen-Dick R, Peterman A, Quisumbing A, Seymour G, Vaz A. The women's empowerment in agriculture index. World Dev. 2013;52:71-91.

47. Kamiya Y, Nomura M, Ogino H, Yoshikawa K, Siengsounthone L, Xangsayarath P. Mothers' autonomy and childhood stunting: evidence from semi-urban communities in Lao PDR. BMC Women's Health. 2018;18(1):70. https://doi.org/10.1186/s12905-018-0567-3.

48. Bhagowalia P, Menon P, Quisumbing AR, Soundararajan V. Unpacking the links between women's empowerment and child nutrition evidence using nationally representative data from Bangladesh. 2010. https:// ageconsearch.umn.edu/record/61273/.

49. Yaya S, Odusina EK, Uthman OA, Bishwajit G. What does women's empowerment have to do with malnutrition in Sub-Saharan Africa? Evidence from demographic and health surveys from 30 countries. Glob Health Res Policy. 2020;5(1):1-11. https://doi.org/10.1186/s4125 6-019-0129-8.

50. Shroff MR, Griffiths PL, Suchindran C, Nagalla B, Vazir S, Bentley ME. Does maternal autonomy influence feeding practices and infant growth in rural India? Soc Sci Med. 2011;73(3):447-55. https://doi.org/10.1016/j. socscimed.2011.05.040.

\section{Publisher's Note}

Springer Nature remains neutral with regard to jurisdictional claims in published maps and institutional affiliations.

\footnotetext{
Ready to submit your research? Choose BMC and benefit from:

- fast, convenient online submission

- thorough peer review by experienced researchers in your field

- rapid publication on acceptance

- support for research data, including large and complex data types

- gold Open Access which fosters wider collaboration and increased citations

- maximum visibility for your research: over 100M website views per year
}

At $\mathrm{BMC}$, research is always in progress.

Learn more biomedcentral.com/submissions 